Agricultural Journal 6(5): 226-230, 2011

ISSN: $1816-9155$

(C) Medwell Journals, 2011

\title{
Production of Citric Acid from Apple Pomace by Using Surface Culture Method
}

\author{
${ }^{1}$ Mohammadyar Hoseyini, ${ }^{1}$ Narmela Asefi and ${ }^{2}$ Mansoureh Mozaffari \\ ${ }^{1}$ Department of Food Engineering, Faculty of Agriculture, Islamic Azad University, \\ Tabriz Branch, P.O. Box 51575-5114, Tabriz, Iran \\ ${ }^{2}$ Department of Agricultural Engineering Research, \\ Agricultural and Natural Resources Research Centre, Tabriz, Iran
}

\begin{abstract}
Due to increasing price of hydrocarbons and difficult access to them, process based on hydrocarbonate substrate has been shifted to design process on the base of waste agriculture carbohydrate such as apple pomace, coffee husk, wheat straw, pineapple waste, mixed fruit, bagasse to produce citric acid. Apple pomace is a suitable substrate for microbial production of citric acid, Aspergillus niger. In this study, new solid-state bioreactor $\left(22.2 \mathrm{~m}^{3}\right)$ was designed with heat gradients and aeration changes and has successfully been put into operation. The operation of bioreactor was optimized using simplex method of analysis. The result of the present study considering the economical and industrial aspects showed that maximum amount of citric acid was produce under the following conditions: moisture content, $80 \%(\mathrm{w} / \mathrm{w})$; fermentation time, $93.9 \mathrm{~h}$; aeration rate, $1.2\left(\mathrm{~L} \mathrm{~min}^{-1}\right)$; nitrogen source (ammonium sulfate), $0.19 \%(\mathrm{w} / \mathrm{w})$ and plate distance, $7.4 \mathrm{~cm}$. Under optimized conditions, $159.14 \mathrm{~g}$ citric acid was produced from $1 \mathrm{~kg}$ dry apple pomace.
\end{abstract}

Key words: Solid state fermentation, citric acid, Aspergillus niger, apple pomace, optimization, Iran

\section{INTRODUCTION}

Citric acid (2-hydroxy propane, 1-3-tri carboxylic acid) with a molecular weight of 210.14 Dalton is a commercial chemical fermentation compound with a high production rate due to the high demands for it. About $70 \%$ of produced citric acid is used in food industry, $12 \%$ in medicine and $18 \%$ in other industrial fields (Hang and Woodams, 1985). So, optimizing effective fermentation factors is of great importance in fermentation progress and from economical aspects. Immersed fermentation by Aspergillus niger fungus filaments is generally used for commercial citric acid production (Hang and Woodams, 1985; Kumagai et al., 1981; Shankaranand and Losane, 1993).

Due to the increasing price of hydrocarbons and the lack of easy access to them, a hydro carbonate substrate based design has been replaced by an agricultural carbohydrate waste design, using apple or grape pomace (Robinson and Nigam, 2003; Lu et al., 1997; Alben and Erkmen, 2004).

Apple pomace is a product of processed apple. Apple pomace consists of the compact cake from processed apple to produce apple juice and concentrate. The compact cake includes waste apple peel and flesh and can be used for making dried, frozen and compote products. Nearly, about $36 \%$ million ton of apples are produced in
USA annually (statistics of 1984) and they provide almost $45 \%$ of total apple production. Apple pomace is used in fuels and chemical food materials. Fresh apple pomace is an acid substrate with significant mean capacity which facilitates microorganism growth for its high moisture content (Chaudary et al., 1978; Tran and Mitchell, 1995; Shojaosadati and Babaeipour, 2002; Roukas, 1999; Couto and Sanroman, 2006; Shankaranand and Losane, 1994). Solid state fermentation was first introduced by Cahn in 1935 in which microorganisms grow in low moisture and dissolved environment. This method needed less energy, investment and operational costs but had more yield than other acid production methods. This study aimed at optimizing citric acid production by a new surface culture using solid state fermentation of the apple pomace. In this method both substrate sides were aerated inside a fermentor. So, the production exposure to the air and fresh oxygen increased, $\mathrm{CO}_{2}$ and substrate heat were removed, mass and heat transfers were aligned and microorganism growth and citric acid production increased.

A reactor in this project was a plastic rectangular cube container made in the laboratory with two vertical cells. The substrate was fixed in the cells and aerated from both sides by the net plates around it. Because of no need for stirring, microorganism and substrate destruction did not occur in this method.

Corresponding Author: Mohammadyar Hoseyini, Department of Food Engineering, Faculty of Agriculture, Islamic Azad University, Tabriz Branch, P.O. Box 51575-5114, Tabriz, Iran 


\section{MATERIALS AND METHODS}

Microorganisms: Aspergillus niger A was provided from Agriculture Faculty of Orumiyeh university. This microorganism was then introduced linearly in PDA culture environment, put in an incubator at $30^{\circ} \mathrm{C}$ for 4 days and stored in a refrigerator at $4^{\circ} \mathrm{C}$. The culture was repeated every 10 days.

Sub strate: Fresh apple pomace was bought from Shahdab juice factory of Orumiyeh, stored at $-18^{\circ} \mathrm{C}$ in sard serw refrigerating room on Nazloo road, dried by $55^{\circ} \mathrm{C}$ hot air until getting to the moisture content of $6 \%(\mathrm{w} / \mathrm{w})$ and stored at room temperature to be used later.

Inoculation: $\mathrm{CA}_{1}$ Aspergillus niger mould spores were mixed with $10 \mathrm{~mL}$ of $30^{\circ} \mathrm{C}$ distilled water in the presence of a flame. Then a spore suspension was prepared and spore numbers reached to 10 spore $\mathrm{mL}^{-1}$ by Lam Newbar method.

Fermentation: After adding some additives, the $2 \mathrm{~mm}$ substrate was sterilized in an autoclave at $121^{\circ} \mathrm{C}$ for $15 \mathrm{~min}$. The inoculated substrate by spores at sterile conditions and ethanol were put in a sterilized fermentor by UV and reactor cells, respectively. All experimental temperatures at different time periods were controlled. After loading the reactor, the system was closed completely. After fermentation, fermented materials were extracted by $30^{\circ} \mathrm{C}$ distilled water. Then citric acid and sugars were analyzed.

Introducing solid reactor: A plastic solid reactor with the length, width and height of 37,20 and $30 \mathrm{~cm}$, respectively was made in the laboratory. Figure 1 shows a three dimensional view of the fermentor designed by 3DS Max software.

This system had an aquarium pump (no. 1), thermal sensor (no. 4), thermometer (no. 5), filter (no. 2 and 6), air moisturizer container (no. 3) and air pomp and aeration pipes (no. 7) which facilitated fermentation. In this research, aeration operation was done moistly so, the erlans containing distilled water were used for air moisturizing.

Since, laboratory atmosphere contained different microorganisms and their spores, a filter was used for sterilizing the incoming air to the fermentor. The inner container temperature was kept stable at $30^{\circ} \mathrm{C}$ by a thermometer and thermal sensors in the system. That fermentor was equipped with two cells for substrate fermentation and $\mathrm{d}$ was plate distance $(\mathrm{cm})$ which was changing and occupied by the substrate. The designed

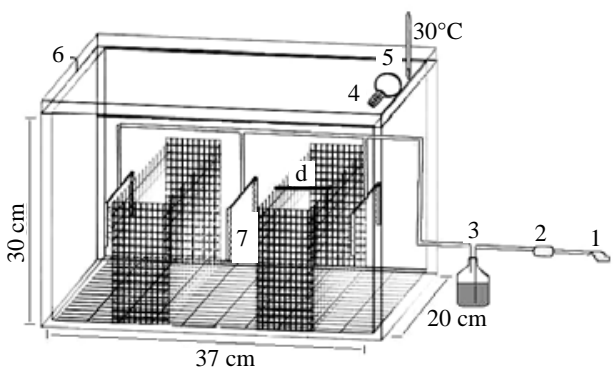

Fig. 1: Three-dimensional view of the reactor

pump was of aquarium type that passed moisturized air inside the reactor, repelled volatile materials and metabolic heat of fermentation which presented production growth. Aeration also reduced substrate drying. Its Debbie was determined by a flow meter $\left(\mathrm{L} \mathrm{min}^{-1}\right)$. Then the substrate was put in the middle of perpendicular net plates and aerated from both sides.

Measuring methods: Pomace moisture content was reduced in a paster oven to get a fixed weight. Reducing sub strate moisture content to the experimental moisture was done according to the mass and material rules and engineering principals.

Regenerator and total sugars were determined by Sumugi Nelson and phenol sulphuric methods, respectively. Citric acid content was determined by a spectrophotometer and pyridine and anydric asetic according to Boulet-Mayer method.

Experimental design: Experiments were optimized by one of the most famous optimization methods called Simplex method. It is the simplest matter in $\mathrm{n}$-dimensional space and does not limit experimental factors. Fixed simplex is the most common and simplest method of simplex optimization (Lu et al., 1997; Sakurai et al., 1997; Shojaosadati and Babaeipour, 2002; Smogyi, 1952; Bereton, 2007; Nair et al., 1995).

Experimental factor design by optimizing a new reactor system, considering aeration rate $\left(\mathrm{L} \mathrm{min}^{-1}\right)$, moisture content $(\mathrm{w} / \mathrm{w})$, nitrogen percentage $(\mathrm{w} / \mathrm{w})(\%)$, fermentor plate distance $(\mathrm{cm})$ and fermentation time $(\mathrm{h})$ is shown in Table 1.

\section{The major effects of operational parameters on citric acid production}

Aeration rate effect: Figure 2 shows aeration rate effects on citric acid production in the new reactor. The results show that aeration rate is significantly affected by citric acid production. Although, higher aeration rate should 
Agric. J., 6(5): 226-230, 2011

Table 1: The fractional-factorial design for optimization of fermentation

\begin{tabular}{lcccccc}
\hline Runs & $\begin{array}{c}\text { Moisture } \\
(\mathrm{w} / \mathrm{w})(\%)\end{array}$ & $\begin{array}{c}\text { Air rate } \\
\left(\mathrm{L} \mathrm{min}^{-1}\right)\end{array}$ & $\begin{array}{c}\mathrm{N}(\mathrm{w} / \mathrm{w}) \\
(\%)\end{array}$ & $\begin{array}{c}\text { Plate } \\
\mathrm{d}(\mathrm{cm})\end{array}$ & $\begin{array}{c}\text { Time } \\
(\mathrm{h})\end{array}$ & $\begin{array}{c}\text { Citric acid } \\
\left(\mathrm{g} \mathrm{kg}^{-1}\right)\end{array}$ \\
\hline 1 & 65.0 & 0.5 & 0.05 & 5.0 & 48.0 & 21.562 \\
2 & 69.6 & 0.6 & 0.06 & 5.4 & 50.5 & 66.180 \\
3 & 66.0 & 1.0 & 0.06 & 5.4 & 50.5 & 43.031 \\
4 & 66.0 & 0.6 & 0.10 & 5.4 & 50.5 & 52.365 \\
5 & 66.0 & 0.6 & 0.06 & 6.8 & 50.5 & 30.336 \\
6 & 66.0 & 0.6 & 0.06 & 5.4 & 58.9 & 60.019 \\
7 & 68.5 & 0.8 & 0.08 & 6.4 & 56.3 & 68.234 \\
8 & 70.2 & 1.0 & 0.10 & 7.1 & 60.5 & 109.678 \\
9 & 69.1 & 0.9 & 0.09 & 4.7 & 57.9 & 87.276 \\
10 & 70.3 & 0.5 & 0.10 & 5.8 & 60.8 & 117.332 \\
11 & 72.5 & 0.3 & 0.12 & 6.0 & 66.0 & 122.373 \\
12 & 72.9 & 0.8 & 0.08 & 6.0 & 67.0 & 123.679 \\
13 & 76.4 & 0.9 & 0.07 & 6.3 & 75.3 & 134.694 \\
14 & 77.1 & 0.9 & 0.12 & 6.4 & 65.1 & 126.106 \\
15 & 78.0 & 1.0 & 0.15 & 6.8 & 68.2 & 130.400 \\
16 & 76.5 & 1.0 & 0.14 & 6.7 & 79.4 & 144.588 \\
17 & 80.0 & 1.2 & 0.19 & 7.4 & 93.9 & 159.150 \\
18 & 78.3 & 0.8 & 0.14 & 7.6 & 79.3 & 144.215 \\
19 & 80.2 & 0.7 & 0.14 & 6.5 & 83.7 & 146.642 \\
20 & 81.3 & 1.2 & 0.13 & 7.3 & 86.2 & 148.322 \\
21 & 81.4 & 1.1 & 0.15 & 7.7 & 102.3 & 161.390 \\
22 & 83.6 & 1.1 & 0.16 & 8.3 & 120.9 & 160.830 \\
23 & 83.6 & 1.2 & 0.23 & 8.6 & 110.3 & 161.950 \\
24 & 87.2 & 1.3 & 0.31 & 9.7 & 127.7 & 159.523 \\
25 & 82.3 & 1.3 & 0.20 & 7.7 & 118.6 & 161.203 \\
\hline
\end{tabular}

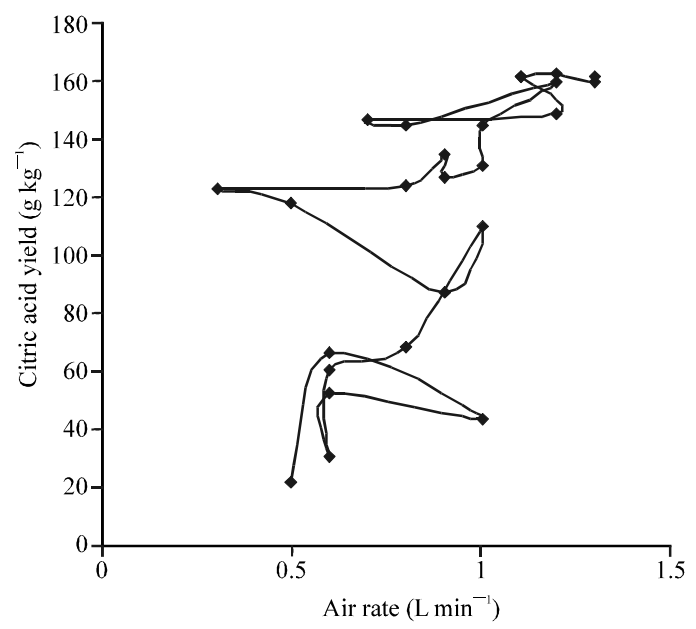

Fig. 2: Aeration rate effects on citric acid production

increase citric acid yielding, the curve shows a negative relation between them. This is for cross-sectional forces of citric acid which have a destructive effect on fungus morphology strings and substrate channels (Shojaosadati et al., 1999).

Moisture content effect: Figure 3 shows moisture content effect on citric acid production in a new fermentor. There is a correlation between citric acid yield and moisture content increase because it has a direct effect on fungus growth, enzyme activity and substrate accessibility and aligning production yield. In high moisture, the empty

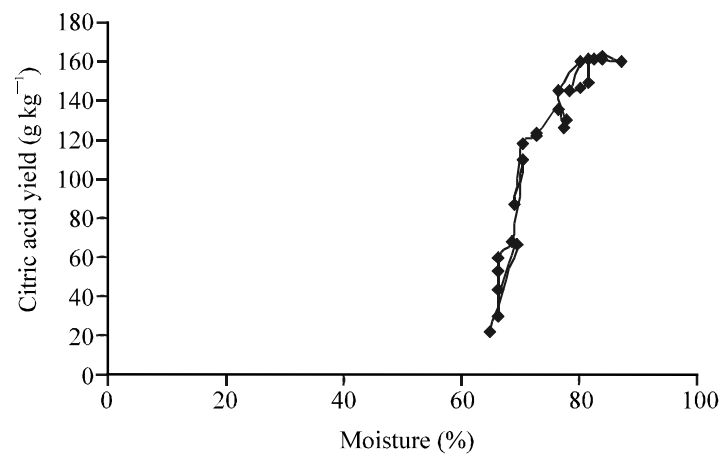

Fig. 3: Moisture effects on citric acid production

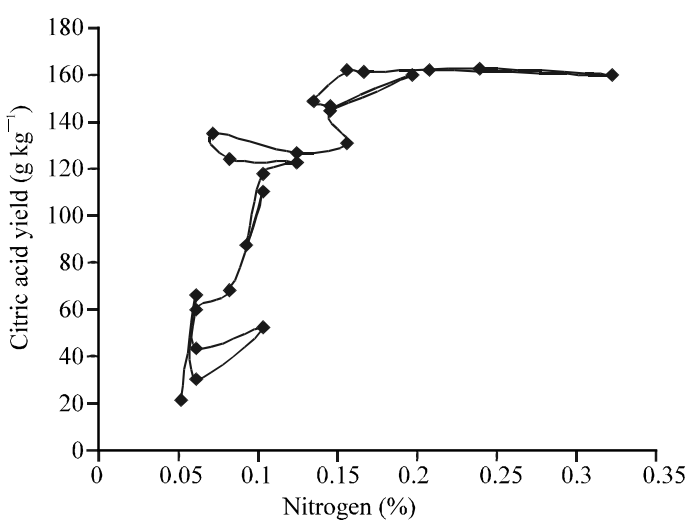

Fig. 4: Nitrogen source effects on citric acid production

spaces among the particles are filled with water and then repel gaseous phase. So, it prevents from aeration degasifying which reinforces vacuum conditions. Low moisture prevents from fungus mycelium growth and decreases enzyme activity and nutritional availability because of less substrate inflammation. It also facilitates spore making as the last limiting factor of fungus growth (Hang and Woodams, 1987; Kargi et al., 1985; Ngadi and Correia, 1992).

Nitrogen source content effect: Figure 4 shows azote content effect on citric acid in a new bioreactor. About $8-14 \%$ microorganism dry weights belong to nitrogen which is usable in both its organic and non-organic forms in the culture environment and is also very effective in citric acid production.

Shortage of nitrogen in culture environment decreases citric acid production. Any increase or decrease in nitrogen concentration, causes fungus growth damage and less citric acid production. Generally, considering general information of the process, citric acid production needs investigating nitrogen content discussions (Pintado et al., 1993; Ali et al., 2002). 


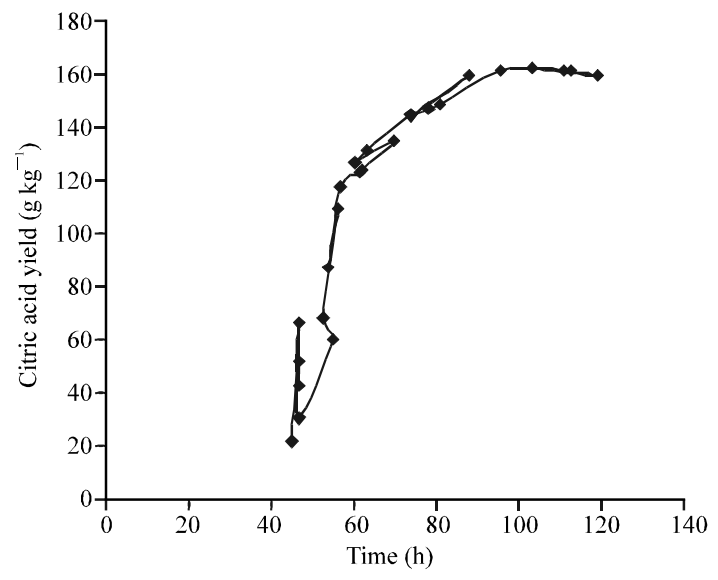

Fig. 5: Fermentation time effects on citric acid production

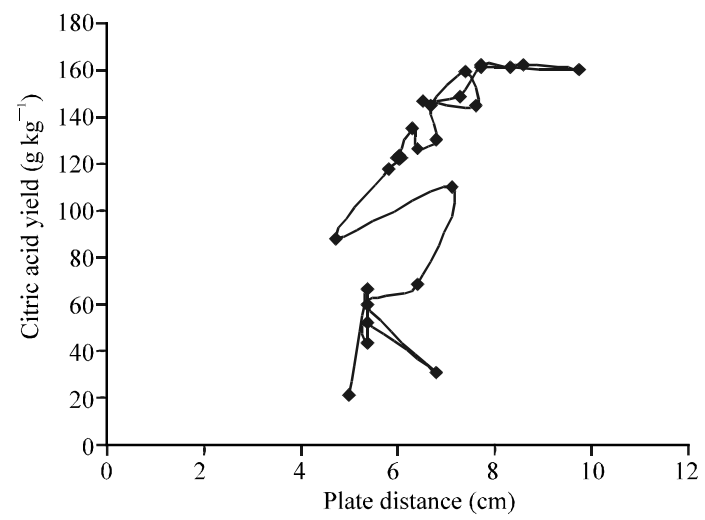

Fig. 6: Plate distance effects on citric acid production

Fermentation time effect: Figure 5 shows time effects on citric acid production. Citric acid is the initial metabolic product which forms in 3-carboxilic acid cycle. Citric acid production kinetic in Aspergillus niger CA1 has two definite respective stages called trophophase and idiophase.

At the 1st stage (trophophase), a part of added glucose is used as a carbon source to produce fungus mycelium and is changed into $\mathrm{CO}_{2}$ and then released. At the 2nd stage (idiophase) the remaining glucose changes into the organic acids (citric acid) and fungus respirations become minimum. The correlation between citric acid production and cellular growth in different stages shows the changeability of this procedure in different processes and physiochemical conditions. Considering the biochemistry of citric acid fermentation, acid accumulation starts when the growth stops (i.e., the maximum production belongs to the cells which are not in growth phase).

It was considered that the time of maximum production in immersed, surface cultures and half-solid cultures change between 6-15 and 3-10 days, respectively. There is a maximum point for citric acid production in different time periods. By passing that max. point, citric acid production decreases in the culture environment because much time causes the decrease of nitrogen and sugars in the substrate (Chaudary et al., 1978; Hang et al., 1978; Hang and Woodams, 1986).

Plate distance effect: Figure 6 shows plate distance effect on citric acid in the fermentor cell. The maximum citric acid production was in the distance of $8.6 \mathrm{~cm}$. Considering aeration force, little space between the plates caused tearing of the fungus mycelium and drying substrate moisture while in more distances, aeration force does not penetrate inside the substrate, fermentation does not occur well and citric acid production decreases (Shojaosadati et al., 1999).

\section{CONCLUSION}

The results of this research from industrial and economical aspects showed that the maximum citric acid (gram acid per kilogram dry pomace) was produced by Aspergillus niger in $80 \%$ moisture $(\mathrm{w} / \mathrm{w}), 93.9 \mathrm{~h}$ fermentation time, $\mathrm{L} \mathrm{min}^{-1}$ aeration rate, $19 \%$ nitrogen source (ammonium sulfate) $(\mathrm{w} / \mathrm{w})$ and $7.4 \mathrm{~cm}$ reactor or plate distance and it reached to 159.15 which was $83 \%$ of total substrate sugar according to glucose. This number had a more significant increase than previous researches. Due to the growing need for citric acid production (about 5000 ton) industrial designing and performing of this process seems necessary. If the raw materials of citric acid production in liquid (immersed and surface) and solid cultures by using apple pomace malase are compared, it will be observed that using solid culture and apple pomace is more economical. Complicated systems needed in liquid (specially immersed) cultures, high sterile conditions, inoculation necessity, high consumption, high sensitivity, low yielding, high levels of needed mechanic and electronic energies, high sewage content and show the superiority of solid culture to the other methods in citric acid production.

\section{REFERENCES}

Alben, E. and O. Erkmen, 2004. Production of citric acid from a new substrate undersized semolina by Aspergillus niger. Food Technol. Biotechnol., 42: $19-22$.

Ali, S., Ikram-ul-Haq, M.A. Qadeer and J. Iqbal, 2002. Production of citric acid by Aspergillus niger using cane molasses in a stirred fermentor. Elect. J. Biotechnol., 5: 258-271. 
Bereton, R.G., 2007. Experimental Design. In: Applied Chemometrics for Scientists. Bereton, R.G. (Ed.). John Wiley and Sons, Ltd., New York.

Chaudary, K., S. Ethiraj, K. Lakshminaray and P. Tacro, 1978. Citric acid production from Indian cane molasses by Aspergillus niger under solid state fermentation condition. J. Ferment. Technol., 56: 554-557.

Couto, S.R. and M.A. Sanroman, 2006. Application of solid-state fermentation to food industry: A review. J. Food Eng., 76: 291-302.

Hang, Y.D. and E.E. Woodams, 1985. Grape pomace a novel substrate for microbial production of citric acid. Biotechnol. Lett., 7: 253-254.

Hang, Y.D. and E.E. Woodams, 1986. Solid state fermentation of apple pomace for citric acid production. World J. Microbiol. Biotechnol., 2: 283-287.

Hang, Y.D. and E.E. Woodams, 1987. Effect of substrate moisture content on fungal production of citric acid in a solid state fermentation system. Biotechnol. Lett., 9: 183-186.

Hang, Y.D., B.S. Luh and E.E. Woodams, 1978. Fermentation of kiwifruit peel. J. Food Sci., 52: 226-227.

Kargi, F, J.A. Cume and J.J. Sheedan, 1985 1985. Solidstate fermentation of sweet sorghum to ethanol. Biotechnol. Bioeng., 27: 34-40.

Kumagai. K., S. Usmai and S. Hattori, 1981. Citric acid production from mandarin orange waste by solid culture of Aspergillus niger. Hakkokogaku, 59: 461-464.

Lu, M., J.D. Brooks and I.S. Maddox, 1997. Citric acid production by solid-state fermentation in a packedbed reactor using Aspergillus niger. Enzym. Microb. Technol., 21: 392-397.

Nair, S.R., S.K. Rakhshit and T. Panda, 1995. Statistical optimization of medium componenets for improved synthesis of pectinase by Aspergillus niger. Bioprocess Eng., 16: 1337-1340.
Ngadi, M.O. and L.R. Correia, 1992. Solid-state ethanol fermentation of apple pomace as affected by moisture and bioreactor mixing speed. J. Food Sci., 57: 667-670.

Pintado, J., M.A. Murado, M. Gonzalez, J. Miron and L. Pastrana, 1993. Joint effect of nitrogen and phosphorus concentrations on citric production by different strains of Aspergillus niger grown on an effluent. Biotechnol., 15: 1157-1162.

Robinson, T. and P. Nigam, 2003. Bioreactor design for protein enrichment of agricultural residues by solid state fermentation. Biotechnol., 13: 227-280.

Roukas, T., 1999. Citric acid production from carob pod by solid-state fermentation. Enzyme Microb. Technol., 24: 54-59.

Sakurai, M., M. Itoh, M. Sakakibara and H. Satio, 1997. Colorimetric methods for determination of sugar and related substances. J. Chem. Technol. Biotechnol., 70: $157-162$.

Shankaranand, V.S. and B.K. Losane, 1993. Sugarcane pressmud as a novel substrate for production of citric acid by solid-state fermentation. World J. Microbiol. Biotechnol., 9: 337-380.

Shankaranand, V.S. and B.K. Losane, 1994. Coffee husk an expensive substrate for production of citric acid by Aspergillus niger in solid-state fermentation system. World J. Microbiol. Biotechnol., 10: 165-168.

Shojaosadati, S.A. and V. Babaeipour, 2002. Citric acid production from apple pomace in multi-layer packed bed solid-state bioreactor. Process. Biochem., 37: 909-914.

Shojaosadati, S.A., R. Faraidouni, A. Madadi-Nouei and I. Mohammadpour, 1999. Protein enrichment of lignocellulosic substrates by solid state fermentation using Neurospora sitophila. Resour. Conserv. Recycl., 27: 73-78.

Smogyi, M., 1952. Notes on sugar determination. J. Biol. Chem., 195: 19-23.

Tran, C.T. and D.A. Mitchell, 1995. Pineapple waste a novel substrate for citric acid production by solidstate fermentation. Biotechnology, 17: 1107-1110. 